\title{
Knowledge about dementia in South Korean nursing students: a cross-sectional survey
}

\author{
Jung Ha Shin ${ }^{1}$, Hyun-Ju Seo ${ }^{2 *}$ Kye Ha Kim² ${ }^{2}$ Kyoung-Hoon Kim ${ }^{3}$ and Youngjin Lee ${ }^{4}$
}

\begin{abstract}
Background: The number of individuals with dementia is increasing substantially due to South Korea's rapidly aging society. Undergraduate nursing students need to have adequate knowledge about dementia to deliver appropriate nursing services. The purpose of this study was to assess the knowledge about dementia among undergraduate nursing students.
\end{abstract}

Methods: A total of 148 students ranging from freshmen to seniors at a nursing university participated in this study. Data were collected through self-reports using 12-item questionnaires with true/false responses. Knowledge levels about the general characteristics including demographic categories and dementia- related education and training were determined. Factors affecting the score of dementia knowledge were also investigated.

Results: The average score and standard deviation for knowledge about dementia were 10.26 and 1.24 out of 12 points. They had relatively low knowledge about the "prevention and treatment" and "causes" of dementia, with overall correct rate of $78.6 \%$ and $85.4 \%$, respectively. Higher level of knowledge about dementia was associated with increase in grade level $(p<0.001)$, experience in education on dementia $(p=0.01)$, previous experience in caring for people with dementia during clinical practice $(p<0.001)$, and acquiring information on dementia $(p=0.02)$. Factors that influenced knowledge about dementia included grade level and experience in caring for dementia patients during clinical practice.

Conclusions: This study showed that the level of knowledge about dementia among nursing students was reasonably good. Integrating dementia education and clinical experience into the curricula of undergraduates could improve knowledge about the causes, prevention, and treatment methods for dementia.

Keywords: Dementia, Knowledge, Nursing students

\section{Background}

There is a worldwide increase in the number of dementia patients [1]. In South Korea, the prevalence of dementia among older adults over 65 years old was approximately $9.18 \%$ in 2012. And the number of dementia patients is expected to double every 20 years; An estimated 1.27 and 2.71 million will be afflicted in 2030 and in 2050, respectively [2]. Because the prevention, management, and treatment of people with dementia have become an important national issue without being limited to

\footnotetext{
* Correspondence: shj5th@korea.ac.kr

${ }^{2}$ Department of Nursing, College of Medicine, Chosun University, 309

Pilmum-daero, Dong-gu, Gwangju 61452, South Korea

Full list of author information is available at the end of the article
}

individual anymore, Dementia Control Act was established in February 2012 [3]. As the number of dementia cases is increasing, the chance of nursing university students to directly interact and care for dementia patients is also increasing. A key strategy to develop a workforce capable of providing care for people with dementia is by educating health professionals to improve their understanding about this complex condition [4].

In spite of the increasing burden from dementia, dementia-care related education in nursing universities has been limited to short-term courses or modules instead of detailed coursework in the continuing education system for professional training [5]. A study targeting 
nurses working at training hospitals has mentioned the need to improve the level of knowledge about dementia because participants only can score 10.8 points out of 16 points [6]. Another study on nurses working in departments related to dementia has reported that nurses need to improve their knowledge in several areas, including effective communication skills with people with dementia and behavioral assessment [7]. In addition, knowledge about caring for dementia patients and practical education of Korean nurses who work at general and long-term care hospitals was ranked the third among nursing requirements [8].

Therefore, nursing university students need to be prepared to enhance nursing care quality and improve the quality of life of patients with dementia $[9,10]$. Knowledge about dementia has been assessed in various healthcare professionals, including nursing college students [11], psychology students [12], medical students [13], and health science students majoring in occupational therapy and social welfare [9]. However, no assessment has been performed to understand the knowledge about dementia in nursing undergraduates in all grades in South Korea. Therefore, the objectives of this study were: (1) to investigate the baseline level of knowledge about dementia in undergraduate nursing students, and (2) to compare the knowledge level depending on respondents' general and educational training characteristics.

\section{Methods}

\section{Research design}

This study had a cross-sectional design to survey the levels of knowledge about dementia through self-reported questionnaires.

\section{Participants and setting}

The target group was full-time undergraduate students from two nursing universities located in a metropolitan city. We selected the two universities due to convenience in sampling to reduce regional differences in data collection. These universities were operating gerontological nursing education using the regular curriculum with the same credits. The target group consisted of 963 full-time students. For ethical considerations, this research was approved by department dean of subject universities. Voluntary participants were recruited by placing posters in subject universities. Additional recruitments were made through describing this study in nursing classes. After receiving permission from the instructor, the primary investigator described the purpose and procedures of this study to nursing classes. Students who agreed to participate then filled out a consent form to confirm their willingness to participate in the research.

We selected a priori power analysis using one-way analysis of variance (ANOVA) to estimate the sample size in a conservative way. Based on previous studies related to this research $[14,15]$, the effect size was set to large $(d=0.40)$ based on ANOVA ( 4 groups). Accordingly, the sample size would be large than 76 (large effect). We sampled 154 students considering the possibility of non-participation. A total of 151 students participated voluntarily (response rate: $98.1 \%$ ). After excluding three incomplete questionnaires, 148 questionnaires were used for analysis. The 148 participants were considered as an appropriate sample size.

\section{Measurements}

At the time when we performed this research, valid Korean version of measurement instrument was not available to assess the knowledge of dementia among medical or nursing undergraduates. Therefore, the Korean version of Dementia Knowledge Questionnaire developed for lay people and reported as a reliable and valid measure [16] was used in these participants after adding educational and care-related questionnaires [11].

The questionnaire consisted of a total of 12 questions, including three regarding the causes of dementia, four regarding the prevention and treatment of dementia, three regarding the symptom and diagnosis of dementia, and two regarding patient care giving (Table 2). The time for answering each question was set to less than 5 minutes and response was set to be yes or no. The total score ranged from 0 to 12 points, with a high score indicating a high level of knowledge. The Kuder-Richardson 20 score was 0.61 , showing moderate internal consistency and reliability. The item-level content validity index (I-CVI) of the questionnaire was examined by five experts with clinical and research experience in the field of psychiatry $(n=2)$ or gerontological nursing $(n=3)$. Based on this questionnaire [16], the mean knowledge scores of participants who indicated that they had been exposed to the principles of dementia at the undergraduate level was 10.3 (SD 1.24), which was significantly $(p<0.001)$ higher than those of lay people with mean score of 9.0 (SD 2.08).

The general characteristics of participants (gender, age, and course progress level) were recorded. Questions were based on educational factors, including interest in dementia, experience in formal dementia education, hours of dementia education (less than $2 \mathrm{~h}$ vs. more than $2 \mathrm{~h}$ ), presence of family members with dementia, personal experience of caring for dementia patients, experience of caring for people with dementia during clinical practicum, exposure to dementia-related information defined as prior experience, obtaining information from mass media, internet, families, relatives, or educational materials, and the type of specific information sources. 


\section{Data collection}

The current study protocol was approved by the Institutional Review Board of Chosun University (IRB No: IRB-13-037). After obtaining the approval, the researcher directly visited the targeted educational institution and gained preliminary permission from the dean and advisor after explaining the purpose of the study and the study procedure. The researcher then explained the purpose of the study and distributed questionnaires to students who agreed to participate in this research. Participants were required to sign a consent form and answer the questionnaire. A reward (e.g. a pen of one dollar) was given to students upon completing the survey. Confidentiality/anonymity of the questionnaire was maintained. Data were saved in the researcher's personal computer with password for security.

\section{Data analysis}

Descriptive statistics were used to understand the general characteristics, factors related to educational training, and the level of dementia knowledge among participants. Scores on dementia knowledge using KolmogorovSmirnov test $(p<0.001)$ were not normally distributed. Therefore, we converted the total score to natural logarithms. Two-sample test and one-way ANOVA with Scheffe post hoc analysis were used to compare dementia knowledge levels depending on general characteristics factors related to educational training. Multiple linear regression analysis was used to determine factors affecting the score of dementia knowledge. Variables were selected and entered into multivariate model based on results of univariate analyses $(p<0.05)$. To examine the multicollinearity of the regression model, variance inflation factor was determined. A variance inflation factor greater than 10 indicated that the model was inadequate [17]. Data analysis was carried out using IBM SPSS Statistics 23.0 (SPSS, Chicago, Illinois, USA). Statistical significance level was set at $p<0.05$. Marginally significant value was set at $0.05 \leq p<0.1$.

\section{Results}

\section{Participant characteristics}

A total of 148 students were used in this study, including 22 (14.9\%) male students and 126 (85.1\%) female students. Their average age was 21.01 years. The 148 students included 36 (24.3\%) freshmen, 38 (25.7\%) sophomores, 39 (26.4\%) juniors, and 35 seniors (23.6 \%). In characteristics related to educational training, 63 (42.6\%) students had dementia education, and $55.6 \%$ of respondents had exposure to dementia-related education with two or fewer hours of dementia education. A total of $84.1 \%$ of participants answered that they had gained a positive attitude toward dementia care after dementia education. In addition, $42.6 \%$ of respondents had experience in caring for persons with dementia. A total of $62(41.9 \%)$ participants said that they had experience during clinical training session of their program. In addition, $75.0 \%$ of respondents had gained information on dementia from education materials from broadcasting $(43.2 \%)$, the internet $(27.0 \%)$, and family members or relatives $(16.2 \%)$ (Table 1$)$.

\section{Knowledge level about dementia}

The average knowledge level about dementia was $10.26 \pm 1.24$ points out of a total of 16 points, equivalent to a score of 85.5 on a scale of 100. Questions addressing whether "regular exercise reduces the risk of dementia," and whether "because a dementia patient has no ability to judge, the patient does not need any explanation as to how he or she is cared for" received

Table 1 Socio-demographic and dementia related characteristics

\begin{tabular}{|c|c|c|}
\hline Characteristic $(N=148)$ & Number & Percent \\
\hline \multicolumn{3}{|l|}{ Gender } \\
\hline Female & 126 & 85.1 \\
\hline \multicolumn{3}{|l|}{ Grade level } \\
\hline Freshman & 36 & 24.3 \\
\hline Sophomore & 38 & 25.7 \\
\hline Junior & 39 & 26.4 \\
\hline Senior & 35 & 23.6 \\
\hline \multicolumn{3}{|c|}{ Experience of dementia education } \\
\hline Yes & 63 & 42.6 \\
\hline \multicolumn{3}{|c|}{ Average time of Experienced education $(n=63)$} \\
\hline Less than $2 \mathrm{~h}$ & 35 & 55.6 \\
\hline More than $2 \mathrm{~h}$ & 28 & 44.4 \\
\hline \multicolumn{3}{|c|}{ Family member with dementia } \\
\hline Yes & 24 & 16.2 \\
\hline \multicolumn{3}{|c|}{ Experience in caring for persons with dementia } \\
\hline Yes & 63 & 42.6 \\
\hline \multicolumn{3}{|c|}{ Cared for people with dementia during clinical placement } \\
\hline Yes & 62 & 41.9 \\
\hline \multicolumn{3}{|c|}{ Exposure to information on dementia } \\
\hline Yes & 111 & 75.0 \\
\hline \multicolumn{3}{|c|}{ Information sources ${ }^{a}(n=111)$} \\
\hline Broadcasting & 64 & 43.2 \\
\hline Educational resources & 64 & 43.2 \\
\hline Internet & 40 & 27.0 \\
\hline Family/relatives & 24 & 16.2 \\
\hline Newspaper & 21 & 14.2 \\
\hline Magazine & 2 & 1.4 \\
\hline Others & 10 & 6.8 \\
\hline
\end{tabular}

${ }^{\text {a Multiple responses possible }}$ 
the highest score, with $95.9 \%$ of respondents answered correct. The lowest correct answer rate was $37.2 \%$ for the question on whether "some types of dementia can be cured completely". As for the correct answer rates according to knowledge area of dementia, the average correct answer rates in the care giving area, symptoms and diagnosis area, causes of dementia area, and prevention and treatment area were $94.6 \%, 89.0 \%$, $85.4 \%$, and $78.6 \%$, respectively (Table 2 ).

\section{Differences in knowledge level according to general characteristics of participants}

The knowledge level depending on participants' general characteristics and relevant educational training showed that the more advanced courses that the participants were in, the higher their knowledge level $(p<0.001)$. Respondents with educational training experience presented higher knowledge levels $(p=0.01)$ than others. In addition, respondents with patient caring experiences during clinical placement had a significantly $(p<0.001)$ higher knowledge level than those without experience in clinical practice. Respondents with exposure to information on dementia presented a higher $(p=0.02)$ average knowledge level (Table 3).

\section{Factors affecting the score of dementia knowledge}

Our results revealed that factors associated with score of dementia knowledge included grade level (junior vs. freshman: coefficient $=0.06, p=0.02$; senior vs. freshman: coefficient $=0.06, p=0.03$ ) and experience with caring for dementia patients during clinical placement (ever vs. never: coefficient $=0.031, p=0.08$ ). The variance inflation factor in this regression model was less than 2.815. The adjusted $R^{2}$ value was $11.1 \%$ (Table 4 ).

\section{Discussion}

The primary objective of this study was to investigate the knowledge level about dementia among nursing students. Their average knowledge level was found to be favorable, with a score of 10.26 out of a possible 12 points, which was equivalent to 86 points on a scale of 100 points. Their knowledge level in the causes of dementia and the prevention and treatment areas needs to be improved compared to knowledge in care giving and the symptoms and diagnosis of dementia. Several international studies have reported relatively lower levels of knowledge regarding dementia $[9,11,12]$. The level of knowledge about dementia in nursing college students with a three-year course has been reported to be 64.5 points out of 100 points using Alzheimer's Disease Knowledge Scale (ADKS) [11]. Using Alzheimer's disease Knowledge Test (ADKT), it has been reported that college students majoring in health science and social welfare have a mean score 37.0 points out of 100 points [9], and those majoring in psychology have a mean score of 66.0 points [13]. In this study, the knowledge levels of students measured by the Korean version of Dementia Knowledge Questionnaire were relatively higher than those reported in previous studies. This could be due to differences in target populations and the measurement tools. The measurement tool used in this study was developed for the lay public [16]. In contrast, ADKS was developed for university students, health care professionals, and experienced clinical nurses [18]. ADKT was developed for professionals and other health personnel involved in the care of Alzheimer's patients [13]. In addition, the measurement

Table 2 Percentage of correct answers per question on knowledge about dementia

\begin{tabular}{|c|c|c|c|c|}
\hline Category & Questionnaire item & True/false & Item correct (\%) & Overall correct (\%) \\
\hline \multirow[t]{3}{*}{ Causes } & Everyone develops dementia when he or she gets old. & $\mathrm{F}$ & 91.9 & \multirow[t]{3}{*}{85.4} \\
\hline & Alzheimer's disease is the most common cause of dementia. & $\mathrm{T}$ & 78.4 & \\
\hline & Stroke may lead to dementia. & $\mathrm{T}$ & 85.8 & \\
\hline \multirow[t]{4}{*}{ Prevention and treatment } & There is no way to prevent dementia. & $\mathrm{F}$ & 95.3 & \multirow[t]{4}{*}{78.6} \\
\hline & Some types of dementia can be cured completely. & T & 37.2 & \\
\hline & Drugs are useful to treat dementia. & $\mathrm{T}$ & 85.8 & \\
\hline & Regular exercise reduces the risk of dementia. & $\mathrm{T}$ & 95.9 & \\
\hline \multirow[t]{3}{*}{ Symptom and diagnosis } & $\begin{array}{l}\text { If a person remembers well what happened a long time ago, } \\
\text { he or she does not have dementia. }\end{array}$ & $\mathrm{F}$ & 84.5 & \multirow[t]{3}{*}{89.0} \\
\hline & $\begin{array}{l}\text { If a person develops dementia, he or she may experience change } \\
\text { in his or her personality. }\end{array}$ & T & 93.9 & \\
\hline & Dementia can be determined only when strange behaviors appear. & $\mathrm{F}$ & 88.5 & \\
\hline \multirow[t]{2}{*}{ Caregiving } & $\begin{array}{l}\text { If a person develops dementia, it is impossible for him or her to } \\
\text { live with his or her family. }\end{array}$ & $\mathrm{F}$ & 93.2 & \multirow[t]{2}{*}{94.6} \\
\hline & $\begin{array}{l}\text { Because a dementia patient has no ability to judge, the patient } \\
\text { does not need any explanation as to how he or she is cared for. }\end{array}$ & $\mathrm{F}$ & 95.9 & \\
\hline
\end{tabular}


Table 3 Differences in dementia knowledge according to general characteristics

\begin{tabular}{|c|c|c|c|c|c|}
\hline Variables & & $n$ & tor $F$ & $p^{*}$ & Scheffé \\
\hline \multirow[t]{2}{*}{ Gender } & Male & 22 & -0.14 & 0.88 & \\
\hline & Female & 126 & & & \\
\hline \multirow[t]{4}{*}{ Grade level } & First $^{a}$ & 36 & 7.04 & $<0.001^{*}$ & $a, b<c, d$ \\
\hline & Second ${ }^{b}$ & 38 & & & \\
\hline & Third $^{c}$ & 39 & & & \\
\hline & Fourth $^{d}$ & 35 & & & \\
\hline \multirow[t]{2}{*}{ Dementia education } & Yes & 63 & 2.60 & $0.01^{*}$ & \\
\hline & No & 85 & & & \\
\hline \multirow[t]{2}{*}{ Mean hours of education } & Less than $2 \mathrm{~h}$ & 41 & 0.90 & 0.36 & \\
\hline & More than $2 \mathrm{~h}$ & 22 & & & \\
\hline \multirow[t]{2}{*}{ Family member with dementia } & Yes & 24 & -1.27 & 0.21 & \\
\hline & No & 124 & & & \\
\hline \multirow[t]{2}{*}{ Experience in caring for persons with dementia } & Yes & 63 & 0.58 & 0.56 & \\
\hline & No & 85 & & & \\
\hline \multirow[t]{2}{*}{ Cared for people with dementia during clinical placement } & Yes & 62 & -3.79 & $<0.001^{*}$ & \\
\hline & No & 86 & & & \\
\hline \multirow[t]{2}{*}{ Exposure to information of dementia } & Yes & 111 & -2.25 & $0.02^{*}$ & \\
\hline & No & 37 & & & \\
\hline
\end{tabular}

${ }^{*} p<0.05$

Difference was statistically significant between $a, b$ and c, d by Scheffe's post-hoc comparison

instrument used in this study was relatively easy in terms of indexing difficulty, which might have resulted in higher score of dementia knowledge compared to those reported in previous studies.

Our second objective was to examine the mean differences in dementia knowledge by general characteristics and determine the factors related to the educational training. The factor that was the most influential for dementia knowledge was grade level. Experience in caring for people with dementia during clinical placement was marginally significant. Therefore, junior and senior students had more chance to receive dementia-care related education and clinical practices. Our results were consistent with the findings of previous studies targeting nursing undergraduates $[9,11]$ and medical school students [19]. In addition, participants who had received dementia education and clinical placement showed significantly higher dementia knowledge levels than others, corresponding to a previous report that dementia knowledge levels in college students were significantly increased after dementia education programs $[12,14]$. Our results was particularly similar to a previous study on the knowledge of Alzheimer's disease among health care staff [20]. Therefore, it is necessary to provide dementia-care-related educational curricula and clinical training in order to improve the knowledge and skills required for nursing personnel who have direct contact with patients/public across health and social care areas [21].

Table 4 Factors affecting the score of dementia knowledge based on multiple linear regression analysis

\begin{tabular}{|c|c|c|c|c|c|}
\hline Variables & B & SE & beta & $\mathrm{t}$ & $p$ \\
\hline \multicolumn{6}{|l|}{ Grade level } \\
\hline First & referent & & & & \\
\hline Second & 0.01 & 0.02 & 0.06 & 0.65 & 0.51 \\
\hline Third & 0.06 & 0.02 & 0.29 & 2.25 & $0.02^{*}$ \\
\hline Fourth & 0.06 & 0.02 & 0.27 & 2.27 & $0.03^{*}$ \\
\hline Dementia education & -0.01 & 0.02 & -0.06 & -0.53 & 0.59 \\
\hline Cared for people with dementia during clinical placement & 0.03 & 0.02 & 0.16 & 1.75 & $0.08^{* *}$ \\
\hline Exposure to information of dementia & 0.01 & 0.02 & 0.05 & 0.59 & 0.55 \\
\hline
\end{tabular}

$\mathrm{R}^{2}=0.147$, Adjusted $\mathrm{R}^{2}=0.111, \mathrm{~F}=4.065, P=0.001$

${ }^{*} p<0.05$ and ${ }^{* *} p<0.1$ 
The level of dementia knowledge in those who had exposure to dementia information was significantly higher than that in others. The main sources of information depending on grade level of students were mass media (for $70 \%$ of freshmen and $80 \%$ of sophomores) and educational materials (for $74 \%$ of juniors and $79 \%$ of seniors). However, because a majority (54.7 \%) of respondents answered that they had two or fewer hours of dementia education, it was difficult to determine if there was a regular education course regarding dementia. In order to estimate the status of dementia care related education in South Korea, we reviewed a nation-wide survey that investigated the level of gerontological nursing education in bachelor of science nursing programs offered by Korean Universities. Thirty-four $(66.6 \%)$ of 51 respondents at four-year nursing universities reported that gerontological nursing was elective courses, while $54.9 \%$ of participants reported that credits for gerontological nursing were "very insufficient" or "insufficient" [22].

As the prevalence of dementia is expected to continuously increase in the rapid aging society, it is important to raise knowledge level about dementia and train nurses and caregivers so that they can provide appropriate services to dementia patients. Therefore, nursing schools need to operate education programs to provide dementia-care-related education and clinical practicum on dementia, including the symptoms and difficulties of dementia, risk factors, screening and diagnosis, disease progress, influences on life stages of individuals with dementia, impact on family and individual, communications, patient care, treatment and management of the illness, environmental aspects, and equality [21].

Regarding the dementia knowledge levels, students who had family members with dementia showed significantly higher levels than those who did not have family members with dementia. This was in agreement with a previous report that students who lived with older family members with dementia had a higher knowledge level [23]. This could be explained by a previous finding that the pursuit of dementia-related interests or dementia knowledge was increased among those who had family members with dementia [24].

The present study was vulnerable to selection bias because it sampled participants from two nursing universities in the same metropolitan city. Another limitation of this study was that we did not find any plausible tool verified in the Korean context to measure the dementia knowledge level of nursing students. In 2015, a study published the psychometric properties using the Korean version of the Alzheimer's Disease Knowledge Scale (ADKS-K) and determined its applicability for Korean adults [25]. Therefore, we evaluated our study participants using the revised tool aided by education and care related items. Further studies are needed to evaluate the dementia knowledge level of nursing students using methodologies validated in the Korean context. Nevertheless, to the best of our knowledge, this study provided important information. It was the first study that examined the baseline dementia knowledge level of Korean nursing students. In addition, we determined the factors related to education training affecting dementia knowledge.

\section{Conclusions}

The study revealed that the knowledge level about dementia among undergraduate nursing students was good, with a mean point of 10.26 out of a possible 12 points. The knowledge level was significantly higher for senior students and those who had experience with dementia education, obtained dementia information, had experience caring for dementia patients during clinical practice practicum, and had family members with dementia. Factors that could influence the knowledge about dementia included grade level of students and experience in caring for dementia patients during clinical placement. These findings suggest that nursing schools need to introduce and operate dementia care related education programs to improve the dementia knowledge in undergraduate nursing students.

\section{Competing interests}

The authors declare that they have no competing interests.

\section{Authors' contributions}

HJS designed the study and carried out the critical revision of the manuscript. JHS analyzed the data and prepared draft manuscript. KHK and HK participated in the study design and contributed to the critical revision of the manuscript. $Y L$ and JHS re-analyzed the data and contributed to the revision of the manuscript. All authors read and approved the final manuscript.

\section{Acknowledgments}

We thank Prof. Eun Young Do (KWANGJU WOMAN'S UNIVERSITY) and Prof. Hee Suk Seo (DONGANG UNIVERSITY) for their help with undergraduate recruitment. We did not receive any funding to conduct this study.

\section{Author details}

${ }^{1}$ Graduate School of Chosun University, Gwangju, South Korea. ${ }^{2}$ Department of Nursing, College of Medicine, Chosun University, 309 Pilmum-daero, Dong-gu, Gwangju 61452, South Korea. ${ }^{3}$ Department of International Cooperation, Health Insurance Review \& Assessment Service, Seoul, South Korea. ${ }^{4}$ College of Nursing, Korea University, Seoul, South Korea.

Received: 7 January 2015 Accepted: 25 November 2015

Published online: 02 December 2015

\section{References}

1. Alzheimer's Disease International. Dementia Statistics. Retrieved from http:// www.alz.co.uk/research/statistics.

2. Ministry of Health and Welfare. Press release. Revised Act of long-term care insurance reflecting on introduction of special classification of dementia. 2014.

3. Ministry of Government Legislation. Dementia Management Act. 2012.

4. Chang E, Daly J, Johnson A, Harrison K, Easterbrook S, Bidewell J, et al. Challenges for professional care of advanced dementia. Int J Nurs Pract. 2009;15:41-7.

5. Pulsford D, Hope K, Thompson R. Higher education provision for professionals working with people with dementia: a scoping exercise. Nurse Educ Today. 2006;27:5-13. 
6. Lin PC, Hsieh MH, Lin LC. Hospital nurse knowledge of and approach to dementia care. J Nurs Res. 2012;20:197-207.

7. Page $S$, Hope K. Towards new ways of working in dementia: perceptions of specialist dementia care nurses about their own level of knowledge, competence and unmet educational needs. J Psychiatr Ment Health Nurs. 2013:20:549-56.

8. Kim JS, Kim KH, Kim MH, Kim HS. Nurse education needs related to knowledge and practice of gerontological nursing. J Korean Gerontol Nurs. 2010;12:177-89.

9. Kwok T, Lam KC, Yip A, Ho F. Knowledge of Dementia among undergraduates in the health and social care professions in Hong Kong. Soc Work Ment Health. 2011;9:287-301.

10. Eccleston CE, Lea EJ, Mclnerney F, Crisp E, Marlow A, Robinson AL. An investigation of nursing students' knowledge of dementia: A questionnaire study. Nurse Educ Today. 2015;35:800-5.

11. Scerri A, Scerri C. Nursing students' knowledge and attitudes towards dementia - A questionnaire survey. Nurse Educ Today. 2013;33:962-8.

12. Jackson EM, Cherry KE, Smitherman EA, Hawley KS. Knowledge of memory aging and Alzheimer's disease in college students and mental health professionals. Aging Ment Health. 2008;12:258-66.

13. Dieckmann L, Zarit SH, Zarit JM, Gatz M. The Alzheimer's disease knowledge test. Gerontologist. 1988;28:402-7.

14. Kang HY, Chae MJ, Seo HS, Yang KM. The Effect of dementia education program on nursing students. J Korean Acad Soc Nurs Educ. 2013;19:69-77.

15. Lea E, Marlow A, Bramble M, Andrews S, Crisp E, Eccleston C, et al. Learning opportunities in a residential aged care facility: the role of supported placements for first-year nursing students. J Nurs Educ. 2014;53:410-4.

16. Seo HJ, Lee DY, Sung MR. Public knowledge about dementia in South Korea: a community-based cross-sectional survey. Int Psychogeriatr. 2015;27: 463-9.

17. O'Brien RM. A Caution regarding rules of thumb for variance inflation factors. Quality Quantity. 2007:41:673-90.

18. Carpenter BD, Balsis S, Otilingam PG, Hanson PK, Gatz M. The Alzheimer's Disease Knowledge Scale: development and psychometric properties. Gerontologist. 2009;49:236-47.

19. Nagle BJ, Usita PM, Edland SD. United States medical students' knowledge of Alzheimer disease. J Educ Eval Health Prof. 2013;10:4

20. Smyth W, Fielding E, Beattie E, Gardner A, Moyle W, Franklin S, et al. Survey-based study of knowledge of Alzheimer's disease among health care staff. BMC Geriatr. 2013;2:2.

21. Farrelly R. Dementia care: knowledge is power. Br J Nurs. 2014;23:627.

22. Kim CG, Kong EH, Kim SS, Kim SJ, Park YH, Song MS. Gerontological nursing education in BSN programs in South Korea: present status and direction for improvement in the future. J Korean Gerontol Nurs. 2013:15:185-91.

23. Park HJ. A comparison of anxiety, knowledge on dementia, and health promotion behavior between two elderly groups with and without hospitalized dementia patients in family members. Master's Thesis. Incheon: Inha University; 2011

24. Sung MR, Yi MS, Lee DY, Jang HY. Overcoming experiences of family members caring for elderly patients with dementia at home. J Korean Acad Nurs. 2013;43:389-98.

25. Kim EJ, Jung JY. Psychometric properties of the Alzheimer's Disease Knowledge Scale-Korean version. J Korean Acad Nurs. 2015;45:107-17.

\section{Submit your next manuscript to BioMed Central and we will help you at every step:}

- We accept pre-submission inquiries

- Our selector tool helps you to find the most relevant journal

- We provide round the clock customer support

- Convenient online submission

- Thorough peer review

- Inclusion in PubMed and all major indexing services

- Maximum visibility for your research

Submit your manuscript at www.biomedcentral.com/submit 